\title{
АНТИКРИЗИСНОЕ УПРАВЛЕНИЕ КАК НАУЧНОЕ НАПРАВЛЕНИЕ В СИСТЕМЕ УПРАВЛЕНЧЕСКИХ НАУК
}

\author{
(c) 2019 Ряховская Антонина Николаевна \\ доктор экономических наук, профессор Департамента менеджмента, \\ руководитель научной школы «Антикризисное управление» \\ Финансовый университет при Правительстве Российской Федерации, Россия, Москва \\ ректор Института экономики и антикризисного управления, председатель подкомитета \\ по антикризисному управлению Комитета по безопасности предпринимательской деятельности \\ Торгово-промышленной палаты Российской Федерации, член Общественного совета Росимущества \\ E-mail: rectorat_ieay@mail.ru

\section{(c) 2019 Кован Сергей Евгеньевич} \\ кандидат технических наук, доцент, профессор Департамента менеджмента \\ Финансовый университет при Правительстве Российской Федерации, Россия, Москва
}

Научная школа «Антикризисное управление» по функциональному назначению продуцируемых знаний относится к прикладным научным школам, что определяет её главную особенность тесная интеграция научных исследований с управленческой деятельностью экономических субъектов различных уровней, практикой арбитражного управления и профессиональным образованием.

Ключевые слова: антикризисное управление; объекты, задачи, виды; институт банкротства, его проблемы; реабилитация должников.

Приоритетным направлением научной школы «Антикризисное управление» является исследование проблем институтов банкротства и саморегулирования в арбитражном управлении, которые динамично развиваются, однако не обеспечивают эффективность механизма банкротства должников, восстановление их платёжеспособности и реабилитационную направленность процедур несостоятельности, что оказывает негативное влияние на развитие социальноэкономических систем различного уровня. В современных условиях политической и экономической нестабильности, порождающей новые проблемы и противоречия, перед учёными стоят новые задачи по модернизации научнообоснованной экономической составляющей антикризисного управления, совершенствованию законодательной базы института банкротства, развитию методологии восстановительных процедур в целях обеспечения реабилитационной направленности института несостоятельности в Российской Федерации.

Недостаточная теоретическая и методологическая разработанность экономической составляющей антикризисного управления в целом и института банкротства в частности определяют государственно важную необходимость прове- дения дальнейших научных исследований.

\section{1. Развитие антикризисного управления} в Poccuu.

В начале 90-х годов прошлого века появилось новое для России направление в системе управленческих наук - антикризисное управление, побудительной причиной которой стало проведение рыночных экономических реформ и возрождение в стране института банкротства в отношении хозяйствующих субъектов.

После 70-ти лет развития «бескризисной» экономики страна погрузилась в сильнейший экономический кризис, одной из причин которого стал беспрецедентный передел прав собственности на предприятия, которые переходили от государства в частные руки, становясь фирмами, компаниями и т.п. организациями различных организационно-правовых форм и форм собственности. Данный процесс сопровождался тотальными неплатежами, несостоятельностью, разрушением и ликвидацией бизнеса бывших советских предприятий.

В этих условиях институт банкротства потребовался, прежде всего, как инструмент, который мог бы, наряду с механизмом проводимой приватизации использоваться для регулирования передела собственности, а также - как способ 
защиты интересов новых рыночных собственников бывших советских предприятий, которые становились кредиторами и должниками в условиях кризиса экономики. Первый в новой российской истории закон о банкротстве был принят в 1992 году. Одновременно с возрождением банкротства в правовой сфере стала формироваться организационная структура практического применения правовых положений и подготовки специалистов соответствующего профиля. Первые научно-практические задачи в области антикризисного управления были связаны с исследованием зарубежного опыта банкротства, возможностей его применения в России, совершенствованием законодательства и его методологического обеспечения. С развитием института банкротства начало развиваться сопряженное с ним направление предупреждения банкротства, как способ защиты имущественных интересов экономических субъектов от потери собственности и сохранения бизнеса в условиях действия негативных факторов внешней и внутренней среды.

К началу XXI века в России были созданы правовые, финансовые и организационные основы института банкротства, сформировалось т.н. антикризисное сообщество в основном из специалистов - практиков арбитражного управления и ученых экономистов и юристов, занимающихся вопросами развития и правоприменения банкротства в России. В целях совершенствования механизма функционирования рассматриваемого института в 1998 г. и 2002 г. были последовательно приняты два основных закона о банкротстве организаций. Несколько ранее в 1994 г. в РАГС при Президенте РФ была создана научная школа «Антикризисное управление», которая прошла несколько этапов развития до момента ее признания Российской академией естествознания и Института экономики и антикризисного управления (2012 г.), а также Финуниверситетом при Правительстве РФ (2013 г.), некоторые публикации ученых научной школы приведены в списке источников к данной статье.

Относительно благополучные в экономическом отношении годы в начале нового XI века привели к искажению роли и задач антикризисного управления. В частности, банкротство стало восприниматься как частное дело отдельных неудачников - собственников компаний, их менеджмента, а антикризисное управление пытались сводить к одной из стратегий менеджмента.
Далее в представленном материале будет показана несостоятельность данных утверждений о роли и месте антикризисного управления как научного направления и практической деятельности.

Мировой финансовый кризис поставил новые задачи и дал мощный толчок развитию антикризисного направления в науке. Жизнь потребовала практического применения антикризисного управления на разных уровнях экономики, включая, макро-, мезо- и микроуровни. В научном плане было обнаружено сходство процессов возникновения, течения и разрешения кризисов в социально-экономических системах на всех упомянутых выше уровнях с возникновением новых задач, включая разработку и реализацию государственных антикризисных программ и планов (см., например, [1]), исследование проблем моногородов и их градообразующих предприятий, других экономических структур в рыночной экономике, их функционирование в современных условиях, развитие механизмов банкротства граждан, института саморегулирования в экономике вообще и в арбитражном управлении в частности.

Практика потребовала расширения задач антикризисного управления на более ранних периодах предупреждения влияния негативных факторов - антиципативное (опережающее) антикризисное управление, а также на более поздние периоды посткризисного управления - peабилитационное антикризисное управление [2].

\section{2. Основы научной конщепции и ключевые} понятия антикризисного управления.

Объектами антикризисного управления являются социально-экономические системы (далее СЭС) различного уровня - открытые системы, обменивающиеся ресурсами с внешней средой, в качестве которой выступают одновременно природа (физический мир), общество (социум) и другие СЭС. Внешняя среда претерпевает изменения, развивается. Развитие любой СЭС в изменяющейся внешней среде приводит к накоплению противоречий, которые разрешаются в т.ч. через конфликты и кризисы.

Научная концепция антикризисного управления рассматривает кризис в СЭС как ситуацию «перелома», предполагающего решение вопроса дальнейшего существования СЭС. Кроме того, кризис представляет собой реакцию СЭС на опасные факторы развития, когда уровень 
сопротивляемости этой системы позволяет ей за счет имеющихся ресурсов перейти к новой модели (форме) функционирования, при которой данные кризисные факторы уже перестают угрожать жизнеспособности СЭС.

Антикризисное управление - это вид социально-экономического управления, выработанный в целях управления процессами прогнозирования, возникновения, течения и прекращения кризисов в СЭС различного уровня. Предмет антикризисного управления - совокупность методов и механизмов, направленных на противодействие негативным событиям, сопровождающим развитие СЭС, включая:

- применение превентивных мер,

- поддержание функционирования в период кризисного развития,

- смягчение негативных последствий кризисных явлений,

- использование факторов кризисов для развития СЭС.

Основными задачами антикризисного управления в различные периоды развития СЭС являются следующие.

1. В стабильном состоянии - адекватная подготовка к возможным кризисам, анализ рисков и угроз, разработка планов реагирования на неблагоприятные явления, мониторинг и диагностика опасных факторов, реализация превентивных мер для повышения сопротивляемости негативным факторам (создание запаса прочности) на финансовом, организационном и правовом уровне.

2. В преддверии кризиса - применение мер по блокированию или снижению отрицательного воздействия неблагоприятных факторов, мобилизация и использование имеющихся ресурсов (интеллектуальных, финансовых, временных) в целях предотвращения кризисов и, при невозможности предотвращения, смягчение отрицательных последствий кризисов.

3. Во время кризиса - обеспечение работы системы в кризисных условиях, разработка и создание новой модели функционирования, обеспечивающей сохранение жизнеспособности системы на будущее.

4. После кризиса - преодоление потерь и негативных последствий или, если система не может быть сохранена - цивилизованная утилизация элементов разрушенной структуры (своеобразная уборка экономического пространства).

Базовое отличие антикризисного управле- ния от менеджмента кроме различия решаемых задач (см. выше), заключается в разнице приоритетов. В менеджменте приоритетом управления являются интересы системы (фирмы, компании) и их собственников. В антикризисном управлении приоритетом являются интересы внешней среды, где функционирует данная СЭС (в т.ч. фирма и компания), т.е. интересы экономики и общества.

Главная цель антикризисного управления - обеспечить эффективное функционирование экономики в целом и отдельных частей хозяйствующих субъектов, вне зависимости от того, кому они принадлежат, т.е.необходимость обеспечения главное, чтобы оно эффективного функционирования предприятия в независимости от его принадлежности.

\section{3. Основной инструментарий антикри-} зисного управления.

Как любое самостоятельное научное направление, антикризисное управление обладает собственной методологией и инструментарием, позволяющим решать указанные выше задачи [3]. К числу основных методов управления СЭС с учетом различных стадий их развития, в том числе функционирующих под воздействием негативных факторов, относятся следующие:

- оздоровление (реабилитация, восстановление) в том случае, если СЭС обладает потенциалом развития, возможностями выхода на новые уровни функционирования, обеспечивающие ее устойчивость во внешней среде;

- деструкция (ликвидация) при отсутствии потенциала восстановления устойчивости, невозможности эффективного функционирования в изменившихся условиях с одновременной цивилизованной утилизацией ресурсов, ранее сосредоточенных в данной кризисной СЭС.

На практике применяется также еще один сценарий обеспечения функционирования кризисных СЭС, не имеющих потенциала развития,- за счет ресурсов внешних систем (игроков), которые по каким-либо причинам (экономическим, социальным, политическим) заинтересованы в поддержании жизнедеятельности кризисной СЭС.

Базовыми инструментами антикризисного управления являются:

1. Предварительная, заблаговременная подготовка к проявлению и воздействию негативных факторов и кризисных ситуаций, ос- 
новой которой является анализ рисков и определение уязвимостей (стресс-тестирование), разработка планов действий, тренинг менеджеров и исполнителей. Данный антиципативный подход обеспечивает сокращение времени реагирования на опасные события и снижение возможного ущерба.

2. Мониторинг возможных рисков и негативных факторов развития, в основе которого периодический и/или непрерывный во времени сбор, аккумулирование и хранение информации о состоянии СЭС и ее внешней среды. Разработка состава контролируемых показателей и данных для проведения мониторинга зависит от конкретных особенностей СЭС и представляет собой важную научно-практическую задачу антикризисного управления.

3. Диагностика состояния СЭС в ее внешней среде. Данный инструмент взаимосвязан и дополняет указанный выше сбор информации о состоянии объекта управления. В антикризисном управлении принято выделять несколько видов диагностики:

- экспресс - диагностику, обеспечивающую получение оперативной информации о наиболее важных показателях деятельности СЭС;

- регулярный анализ и оценка данных, полученных в результате проводимого мониторинга (в настоящее время проводится в автоматическом режиме как обработка компьютерных баз данных);

- комплексный анализ, в ходе которого рассматриваются и анализируются все стороны жизнедеятельности СЭС, включая производственную, финансовую, маркетинговую, организационную, кадровую и т.д.

4. Заблаговременное накопление ресурсов с целью обеспечения высокого порога сопротивляемости негативным факторам функционирования и развития. Создание «подушки безопасности» позволяет преодолеть первые опасности кризисов, увеличить время на принятие научно обоснованных управленческих решений по противодействию последующим факторам.

5. Прямая финансовая, кадровая, административная поддержка СЭС со стороны внешних систем, включая государство. Финансовая поддержка получила название - санация.

6. Реструктуризация, представляющая существенное переформатирование СЭС в части изменения бизнеса, имущественного комплекса, прав собственности, системы управления и структуры обязательств. В отличии от реструктуризации, проводимой в компаниях в стабильном состоянии в целях развития и получения конкурентных преимуществ, в данном случае речь идет об антикризисной реструктуризации, которая имеет целью возврат в стабильное состояние, носит срочный и вынужденный характер.

Особое значение получила разновидность антикризисной реструктуризации - реструктуризация задолженности, которая применяется как в отношении компаний, интегрированных экономических структур, так и в отношении других должников. Например, на макроуровне реструктуризация задолженности применяется к странам, являющимся экономическими должниками других стран и/или международных финансовых организаций.

\section{4. Задачи и проблемы, решаемые анти-} кризисным управлением в настоящее время.

В разные периоды развития перед антикризисным управлением ставились различные задачи, с учетом актуальных проблем для экономики государства в целом, в решении которых принимали участие ученые научной школы «Антикризисное управление».

\section{На макроуровне.}

1. Исследование практики функционирования системы государственного антикризисного регулирования, включающего правовое, организационное, финансовое составляющие. При этом роль государственного антикризисного регулирования заключается в создании такой системы взаимодействия государства и различных субъектов экономики, которая обеспечивает преодоление макро- и микроэкономических кризисов. Государственная политика в сфере регулирования кризисных ситуаций должна заключаться в выработке и реализации стратегии развития государства и общества, направленной на преодоление кризисных ситуаций и обеспечение равновесного состояния институтов экономической системы и государственной системы (власти).

В настоящее время, в период, когда по выражению В.В. Путина «мир вступает в зону турбулентности и, безусловно, этот период будет длительным и болезненным» [10], ситуация усложняется наличием кризисных явлений и в мировой экономике. Эти обстоятельства свидетельствуют о значительной актуальности задач 
совершенствования подходов государственного антикризисного регулирования [4].

2. Анализ и развитие института саморегулирования в России на основе изучения российской практики, зарубежного опыта саморегулирования, в основном на примере саморегулируемых организаций арбитражных управляющих [5]. При этом саморегулирование - это важный рыночный институт, который способствует решению многих проблем социально-экономического характера, в том числе развитию и повышению эффективности государственного управления экономическими субъектами.

Совершенствование механизма функционирования института саморегулирования, требует детального изучения результатов деятельности различных профессиональных сообществ и их саморегулируемых организаций. При этом особое значение имеет не только российский, но и зарубежный опыт, особенно тех стран, где институт саморегулирования развивается существенно дольше, чем в России.

3. Развитие антикризисного управления как важного элемента обеспечения экономической безопасности России. Среди основных задач государства, которые необходимо решить с целью преодоления множества внешних и внутренних угроз безопасности, важную роль играет задача обеспечения безопасности экономической деятельности. С этой целью может и должен использоваться институт банкротства субъектов рыночной экономики как один из значимых механизмов воздействия государства на социально-экономические процессы в обществе [6].

Банкротство выполняет следующие важные защитные функции:

- освобождение экономики от неэффективных, убыточных хозяйствующих субъектов (организаций), которые не в состоянии поддерживать бизнес в работоспособном состоянии;

- защита бизнеса от неправомерных и неквалифицированных действий собственников, которые не могут или не имеют желания осуществлять эффективное управление с целью развития бизнеса;

- обеспечение льготных и специальных режимов проведения банкротства в отношении организаций-должников, имеющих системообразующий характер и высокое социально-экономическое значение.

На мезоуровне.
По мнению специалистов научной школы Антикризисное управление, в отношении социально-экономических систем, функционирующих на мезоуровне, наиболее актуальными в настоящее время являются следующие научно-практические задачи.

1. Финансовое оздоровление моногородов и соответствующих градообразующих экономических субъектов. Развитие рыночных отношений в российской экономике сопровождается обострением проблем монопрофильных населенных пунктов, основой существования которых являются градообразующие организации и технологические цепочки организаций, которые создают градообразующую структуру.

Для многих из таких территориально-экономических образований характерно наличие недостаточных конкурентных возможностей, что вызвано особенностями их географического и экономического положения при одновременном наличии высокой социальной ответственности. Возможным вариантом решения проблем антикризисного развития моногородов и их интегрирования в рыночную экономику России является проведение антикризисной реструктуризации экономического комплекса данной территории [7].

2. Исследование особенностей антикризисного управления в отношении интегрированных предпринимательских структур (групп) и альянсов. Создание альянсов различной степени интеграции является магистральным направлением развития субъектов рыночной экономики в настоящее время. Вместе с тем вхождение компании в предпринимательскую группу, холдинг или другую интегрированную структуру, обеспечивая ряд очевидных финансово-экономических преимуществ, требует от компании выполнения различных указаний головной организации группы, т.е. ряд управленческих функций передается на внешний вышестоящий уровень.

Вместе с тем, в том случае, когда у компаний, входящих в группы и альянсы, возникают финансовые проблемы, используемые в правоприменительной практике инструменты не всегда позволяют разрешить их справедливым и добросовестным образом. Интегрированные структуры в этом случае необходимо рассматривать как единые экономические системы, отвечающие солидарно по обязательствам своих членов [4] 
На микроуровне.

Наиболее актуальными проблемами банкротства экономических субъектов рассматриваемого уровня на современном этапе являются следующие [11]:

1. Низкая результативность реабилитационных процедур банкротства организаций, в отношении которых возбуждено дело о банкротстве - менее 1\% восстановления платежеспособности без учета мирового соглашения должников с кредиторами.

2. Значительные сроки проведения процедур банкротства - как правило более 2-х лет.

3. Слишком малая результативность по возврату кредиторам сумм причитающейся задолженности - в среднем 5-6 копеек на 1 рубль долга.

Как представляется, низкая эффективность и результативность реабилитационных процедур банкротства является следствием наличия значительных недостатков законодательства, что подтверждается правоприменительной практикой. Главной причиной является то, что в своей реабилитационной концепции законодатели пошли по пути реабилитации компаний (организаций), вместо реабилитации работоспособного бизнеса.

В существующем виде реабилитация в банкротстве основана на том, что в период проведения данных судебных процедур за счет кредиторов и за счет фактически похищенного у них времени будет восстановлена платежеспособность организации с ее последующей передачей тем же собственникам, которые и допустили (или довели) компанию до банкротства. При этом за такие реабилитационные процедуры должны проголосовать сами кредиторы.

Очевидно, что в таких ситуациях у кредиторов полностью отсутствует мотивация к реабилитации своих должников. Что касается должников, то об отсутствии у них мотивация к восстановлению платежеспособности в банкротстве свидетельствуют данные статистики [11], по которым число ликвидированных в банкротстве компаний с реализацией их имущества приближается к ста процентам.

Приведенные данные свидетельствуют о том, что собственники не заинтересованы во вхождении в процедуру банкротства, сопротивляются этому до конца с потерей времени и соответственно возможности восстановления платежеспособности проблемных компаний с утратой всех ресурсов на самостоятельную и безнадежную борьбу.

Недобросовестные собственники, желающие использовать институт банкротства в неправомерных целях, также не заинтересованы в реабилитации своих компаний. Их цели противоположны - поскорее войти в ликвидационную процедуру конкурсного производства и списать накопленные долги.

Таким образом, среди участников процесса банкротства практически отсутствуют собственники заинтересованные в реабилитации должника. Исключением здесь являются только социально и экономически значимые организации - стратегические, градообразующие и т.п., в оздоровлении которых заинтересовано государство эффективность и результативность реализации дел о банкротстве которых значительно выше средних результатов по институту банкротства в целом. С 2014 по первую половину 2017 года ликвидационная процедура введена в отношении только 11\% стратегических организаций из числа поданных заявлений, $18 \%$ организаций, являющихся субъектами естественных монополий и 21\% градообразующих организаций.

Ученые научной школы «Антикризисное управление» обосновали целесообразность и направления совершенствования реабилитационной концепции законодательства о банкротстве [8]. С заменой неквалифицированных и/или недобросовестных собственников, и сохранением работоспособного бизнеса, в котором высокопрофессиональном управлении может быть восстановлена платежеспособность и обеспечена самостоятельная рентабельная деятельность.

Таким образом в процедурах банкротства следует защищать работоспособный бизнес не только от нападок кредиторов, но и от неправомерных действий и со стороны неэффективных и недобросовестных собственников, что требует пересмотра отношения к процедуре конкурсного производства, по завершении которой ликвидируется организационно-правовая оболочка бизнеса - организация. При этом важно эффективно распорядиться остающимся имущественным комплексом и интеллектуальными ресурсами, которые бизнес и осуществляет. Последнее можно эффективно проводить с помощью уже имеющихся в законодательстве мероприятий продажи предприятия и замещения активов, которые позволяют реализовать имущественный 
комплекс целиком, передать его новым заинтересованным в развитии данного бизнеса собственникам.

Предлагаемые изменения реабилитационной концепции позволят решить наиболее остро стоящие проблемы института банкротства. По оценкам авторов если бы проводилось статистическое наблюдение за числом реализованных в конкурсном производстве предприятий с сохранением возможности продолжения бизнеса, то эти статистические данные уже сейчас могли бы показать примерно 10\%-30\% реабилитации работоспособного бизнеса.

Переход от реабилитации компаний к реабилитации бизнеса позволил бы отказаться от затратных по времени и бесполезных по сути процедур финансового оздоровления и внешнего управления, которые целесообразно реализовать только в отношении социально и экономически значимых компаний. Также может быть сокращено время на проведение процедуры наблюдения, которая сейчас занимает до 7 месяцев, путем объединения и совмещения задач, которые сейчас решаются в этой процедуре с началом проведения конкурсного производства. Эти меры могут резко сократить время нахождения в процедурах банкротства примерно на $1-1,5$ года.

Реабилитацию организаций можно обеспечить для добросовестных собственников за счет законодательного введения новой процедуры, которая опробована при банкротстве физических лиц - реструктуризация долга, что позволит решить одну из возможных задач института банкротства России - повышение степени удовлетворения требований кредиторов за счет увеличения суммы распределяемых средств, полученных от реализации имущества должника. При этом необходимо учитывать, что реализация работоспособного бизнеса в большей степени увеличивает конкурсную массу, чем распродажа отдельными объектами имущества (в розницу).
На уровне граждан.

Практика проведения процедур банкротства физических лиц подтвердила социально-экономическую значимость и низкий уровень эффективности института банкротства в отношении этой категории должников, наличие множества проблем, которые требуют научно обоснованного и своевременного их решения. Банкротство граждан должно опираться не только на правовые нормы, определенные в законодательстве, но и иметь четкую методологию экономического обоснования и принятия правовых решений в отношении должника гражданина. В настоящее время имеет место существенный пробел именно в методологическом обеспечении института банкротства граждан.

Указанные задачи являются предметом внимания ученых научной школы антикризисного управления.

\section{Заключение.}

Таким образом, антикризисное управление как научное направление в системе управленческих наук по своему функциональному назначению продуцируемых знаний относится к прикладным научным направлениям, что определяет её главную особенность - тесная интеграция научных исследований с управленческой деятельностью экономических субъектов, практикой арбитражного управления и профессиональным образованием.

Одной из приоритетных задач антикризисного управления является исследование проблем института банкротства, который динамично развивается, и в настоящее время стал одним из современных, проработанных отраслей законодательства. Однако наличие множества системных проблем и противоречий требует дальнейшего развития теории и практики антикризисного управления как науки, так одного из важнейших направлений управленческой деятельности.

\section{Библиографический список}

1. Антикризисное управление: современная концепция и инструментарий. Кован С.Е., Ряховская А.Н., // Управленческие науки. 2016. № 3. С. 45.

2. Трансформация антикризисного управления в современных экономических условиях. Монография под редакцией Ряховской А.Н. Москва, Инфра-М.: 2014. Сер. Научная мысль.

3. Антикризисное управление: развитие научного направления и практики. Статья. Ряховская А.Н., Кован С.Е.//Управленческие науки. 2014. № 3. С. 29-37. 
4. Теория антикризисного управления социально-экономическими системами (ресурсный подход). Монография под редакцией С.Е. Кована, Москва, Инфра-М.: 2013. Сер. Научная мысль.

5. Анализ международной практики саморегулирования в отраслях экономики. Монография под редакцией Москва, Кнорус. 2017.

6. Влияние института банкротства на экономическую безопасность государства: вызов или инструмент обеспечения? Ряховская А.Н., Кован С.Е.//Имущественные отношения в Российской Федерации. 2018. № 6 (201). С. 79-89.

7. Совершенствование методов антикризисной реструктуризации градообразующих организаций в муниципальных образованиях. Монография под редакцией А.Н. Ряховской, Волков Л.В., Кован С.Е., Крюкова О.Г., Ряховская А.Н., Березин К.А., Рубанова К.А., Линдер Н.В. Москва, 2016. Инфра-М. Сер. Научная мысль.

8. Антикризисное управление как основа формирования механизма устойчивого развития бизнеса. Монография. Ряховская А.Н., Кован С.Е., Крюкова О.Г., Алферов В.Н., Кочетков Е.П., Смирнова Д.Д. Москва, 2016. Инфра-М. Сер. Научная мысль.

9. Институт банкротства физических лиц: практика и направления развития. Монография под редакцией А.Н. Ряховской, С.Е. Кована. Алферов В.Н., Кован С.Е., Кожевина О.В., Кочетков Е.П., Крюкова О.Г., Кузнецова М.О., Ряховская А.Н., Солдатенков В.Ю. Монография. Москва, Кнорус, 2018.

10. В.В.Путин «Россия сосредотачивается - вызовы, на которые мы должны ответить», Известия 16.01 .2012

11. Статистический бюллетень ЕФРСБ 30 июня 2018 г. URL: https://fedresurs.ru/news/5bd49902-7344-4f03a63e-344994816c5d, дата обращения 07.03.2019 г. 